\title{
Proprioception as a basis for individual differences
}

\section{Liudmila N. Liutsko}

Mira y Lopez Laboratory, University of Barcelona, Barcelona, Spain

\begin{abstract}
In this chapter the author summarises the descriptions of proprioceptive sense from different perspectives. The importance of proprioceptive sense has been shown in developmental psychology, in both the earlier and later stages of individuum formation. The author emphasises in this chapter the role of proprioception as a basis of personality and the individual differences construct. The importance of assessing behaviour at multiple levels has been pointed out by experiments of classic and modern researchers that should include not only verbal tests that would be more important for conscious mental description, but also techniques that could assess other behavioural characteristics, including automatic unconscious and pre-reflexive behaviour. The author also describes the effects of altered proprioception in humans, such as the Pinocchio effect, and other spatial perception distortions. In this chapter the importance of proprioception in acquiring new skills (embodied knowledge) as automatic and conditioned reflexive behaviour has also been highlighted. Finally, the complete picture of the individuum has been presented as a multi-layered level of a body-mind union approach.
\end{abstract}

Key words: proprioception, individual differences, multi-layered personality, embodied knowledge, automatic movements.

The aspects of things that are most important for us are hidden because of their simplicity and familiarity. Wittgenstein (cited in Sacks, 1985)

In the cognitive sciences, the most challenging phenomena are often the ones we take for granted in our everyday lives.

Botvinick (2004)

\section{Definition of proprioception}

The term "proprioception" was introduced by Sherrington (1906), although this basic feeling of ourselves had always been present. Proprioception, or the perception of body awareness, is a sense that people are frequently not aware of, but greatly rely upon. More easily demonstrated than explained, proprioception is the "unconscious" awareness of where the various regions of the body are located at any given time. For example, with closed eyes, we can say where our hands or legs 
are at this moment. Without proprioception we could not bring a spoon bearing soup into the mouth, ride a bicycle, or change the gears of a car without looking at our hands or feet.

\section{Proprioception as described by Sechenov}

In his 1863 work "Refleksi golovnogo mozga" [Reflexes of brain], the renowned Russian physiologist Sechenov called proprioception a "dark muscle sense" (Sechenov, 2013, originally published 1863), and described the role of that muscle sense in the training of vision, hearing and other senses, especially in his work "Elements of Thoughts" (Sechenov, 2013). He demonstrated that spatial vision is formed first of all with the help of proprioceptors of the eye muscles, and secondly, due to multiple evaluation and combination of distance by eyes or legs. As for distance measurements, we still conserve in some countries "proprioceptive" (related to the length of body parts) units like "feet", "inch", or old ones such as ell (originally a cubit, i.e., approximating to the length of a man's arm from the elbow to the tip of the middle finger, or about 18 inches), dactilus or digit, and palm in ancient Greece.

As Sechenov thought, the muscle is not only analysing components of space, but also of time: "Near, far, height of subjects, their traces and velocities - all are the products of the muscle sense... The same muscle sense, being partial (fractioned) in periodical movements, becomes a partial measurement instrument of space and time" (Sechenov, 2013).

Proprioception is tested by Russian neurologists when they ask patients to touch their nose with their finger or walk with their eyes closed along a straight line drawn on the floor. It is also checked by American police officers by having a suspect touch their nose with their finger, with eyes closed, to gauge alcohol intoxication: people with normal proprioception make an error of no more than twenty millimetres.

\section{Effects of alterations in proprioception}

When proprioception is altered, sensitive ataxia can take place, as in the clinical case described by Wingenshtein (Schmidt, 1984), when a patient after an operation had lost her proprioception and gradually forgot how to move or eat, and even stopped breathing. To remain functional, she would compensate for proprioceptive loss by other senses, principally by vision, as in the Ian Waterman case (BBC movie, 1998, The man who lost his body). If proprioceptive impairment takes place due to some body part being missing from one's mental self-image, we need to check it visually (to look down at our limbs, for example) or by touch (to pinch ourselves to feel this part); however, under a complete loss of proprioception in all or a part of body, we simply cannot feel it and may guide ourselves only visually, as in the Ian Waterman case. In order to learn to walk again, he used his eyes and needed to always look at his feet while moving (BBC documentary, 1998, The man who lost his body).

Small proprioceptive alterations are felt when one catches cold or is simply tired. Under vibration or other external/internal stimuli (real and virtual) proprioceptive changes can appear, such as the "Pinocchio effect" (Kilteni, Normand, Sanchez- 
Vives, \& Slater, 2012; Lackner, 1988) when body size perception is altered (perceived as too large or too small). To experience the "Pinocchio Illusion", you need to apply a vibrator to the biceps tendon while one holding your nose with the ipsilateral hand. Muscle stretching occurs due to stimulation of the muscle spindles by the vibrator, creating a kinesthetic illusion of the arm moving away from the face. Since the fingers are still holding the nose, this results in a perception that the nose is moving away from the face also, and thus enlarging. Similar effects (changes of body part sizes) happen during epilepsy or migraine auras, or during changes in gravity when astronauts are passing the frontier of Earth's gravity, or in reactive airplane tests that take the ballistic curve of Kepler (when weightlessness lasts between 20 to $60 \mathrm{sec}-$ onds), as per Lebedev's self-observation (Leonov \& Lebedev, 1965):

Due to motor noise and vibration, I guessed that the airplane was accelerating. After several seconds the overload had occurred... I felt like I was falling down an abysm. This feeling, I estimated as lasting 1-2 seconds... Knowing very well theoretically about difficulties of weightlessness, I expected to spend it badly; however it was a contrary reaction. I felt delight that transformed later into euphoria... Then the overload started again. The state of weightlessness came suddenly and I flew up and then off in an indefinite direction. It was a moment of full disorientation in space. Later I came to recognize the situation. I saw the floor and walls of the room. The latter seemed to be enlarging. The illusion was like looking through inverted binoculars. When I looked at the floor, it was enlarging and shrinking as if escaping and moving from me. At that moment I tried to grab for something. Though the objects seemed to me to be close, I could not reach them and that fact provoked the sharpest emotional excitation."

EGG results proved that weightlessness worked as a powerful excitatory stimulus; for this reason, people who had weak nervous systems had greater space disorientation and felt the "world crush" symptom, while people with strong nervous systems merely felt positive (sthenic) emotions. Moreover, the reactions that appeared during weightlessness flights correlated to reactions in other stressful situations (such as during parachute jumping, etc.). However, even in people with strong nervous systems, these flights through vestibular-proprioceptive stimuli had become habitual, and people could experience emotional-neurotic breakdowns (reactive neurosis) in cases of astenisation and chronic fatigue (Leonov \& Lebedev, 1965).

If proprioception on the first level involves afferent signals to the Central Nervous System (CNS), at the second level it comprises the feeling of body parts as their projection in the cortex. The above-mentioned somatosensory homunculus is also believed to be related to Phantom Limb Syndrome: when a person continues to feel a limb or other amputated part of body (appendix, tooth, etc.) (Ramachandran \& Hirstein, 1998; Phantom limb, 2009). Phantom sensations can occur as passive proprioceptive sensations of the limb's presence, or more active sensations such as perceived movement, pressure, pain, itching or temperature. The missing limb often feels shorter and may feel as if it is in a distorted and painful position. Occasionally, the pain can be made worse by stress, anxiety, and weather changes (Arena, Sherman, Bruno \& Smith, 1990; Phantom limb, 2009), and the intensity and continuity of the illusory perception can depend on individual differences. Thus, positive significant correlations were found between neuroticism and evocation latencies; 
while the intensity and continuity of the illusory sensations were significantly described with more amplitude by extroverts in comparison to introverts (Juhel \& Neiger, 1993).

\section{Awareness of proprioceptive sense and other definitions of proprioception}

Since the proprioceptive sense often goes unnoticed because humans adapt to it (this is an effect of habituation or desensitization to a continuously present stimulus), we can become aware of it when we lose it. Particular cases of induced proprioceptive loss are local anaesthesia before operations: teeth or some part of the body before a surgical intervention. Temporary loss or impairment of proprioception can apparently happen periodically during growth, mostly during adolescence, or may be altered when large increases or decreases in bodyweight/size occur due to fluctuations of fat (liposuction, rapid fat loss, rapid fat gain) and muscle content (bodybuilding, anabolic steroids, catabolises/starvation) or in those who gain new levels of flexibility, stretching, and contortion. Moreover, proprioceptive sense and body size performance related to it can be altered by vibration (Longo, Kammers, Gomi, Tsakiris, \& Haggand, 2009).

At present there is in fact no clear definition of proprioception: apart from being narrowly connected to equilibrioception (balance), proprioception is sometimes interchangeable with kinaesthesia, although the latter specifically excludes the sense of equilibrium or balance, and can be counted as a subset of proprioception (Proprioception ${ }^{a}$, 2007). Although we have always had the basic sense of proprioception, and even though scientists started to pay attention to it at the end of the $19^{\text {th }}$ century, almost hundred years later questions related to proprioception in the article "Where does Sherrington's 'muscular sense' originate?" were still unclear (Matthews, 1982).

Other definitions of proprioception appeared later on. One of them included a broader context of proprioception that was based not only on pure physiological sense, but was also expanded to the "self-perception of thought" in which thought is aware of its movements (Bohm, 2007).

\section{Proprioception as a basis of personality in Allport's theory}

Previously, proprioception was one of the components of "self" ("I") or "ego" that was expanded in the theory of psychology by Gordon Allport (Gordon Allport, 2006), who operated using the term "proprium" ("my own" from Latin) instead. Following his ideas, the development of "proprium" has eight stages to reach maturity, the first of which comprises a proprioceptive awareness that together with interoceptive and touch sense were a basis of the whole "self" or "proprium" construction and development, or "propriate" functions:

1. The Sense of Body or Bodily Self (develops in the first two years of life) is a sense, or awareness, of one's own body and its sensations; it is a basic axis of personality development and an anchor for self-awareness. In this, all bodily organic feelings are included even though we had not been aware of them until some painful or unpleasant sensation appeared. We perceive everything related to our body as something warm, close and pleasant; and everything alien to it as something cold, 
distant and unpleasant. Allport's favourite demonstration of this aspect: Imagine splitting saliva into a cup - and then drinking it down. What is the problem? It's the same stuff that you swallow all day long; however, it has left your bodily self and thereby become foreign to you.

2. The Sense of Self-Identity (develops in the first two years) - is a sense which grows gradually and is most evident when the child, through acquiring language, recognizes himself as a distinct and constant point of reference. First children recognize their name among a flood of sounds, and later they understand that they are the same person despite external (due to growth) and internal (thought) changes.

3. The Sense of Self-Esteem or Pride, which is an individual's evaluation of himself and the urge to want to do everything for oneself and take all the credit. It is an exaltation of the ego; an ego that is inherent to man by nature, and needed for survival. Everyone tends to self-assertion, and must have a sense of pride in themselves, and be self-satisfied. It is a time when we recognise that we have value to others and to ourselves. This is especially tied to the continuing development of our competencies.

4. The Sense of Self-Extension (occurs during the third year of life), which states that even though some things are not inside my physical body they are still very much a part of my life. Certain things, people, and events around us also come to be thought of as central and warm, and essential to existence. Some people define themselves in terms of their parents, spouse, children, clan, gang, community, college or nation. Some find their identity in activities: I am a psychologist, a student, a bricklayer. Some find identity in a place: my house, my home town. When their child does something wrong, parents can feel guilty about it. If someone scratches our car, we can feel like they hit us. While at an early age, the child identifies himself with his parents or joys that "pertain" to him, later this feeling is extended to other social groups (classmates, neighbours, nation). At a mature age this process can be expanded to the processes of development of abstract ideas and moral values.

5. Self-Image (develops between four and six), or how others view "me", is another aspect of selfhood that emerges during childhood. This is the "lookingglass self," as others see me. This is the impression I make on others, my appearance, or my social esteem or status, including my sexual identity. It is the beginning of consciousness, ideal self, and persona.

6. Sense of Self as a Rational Coping being (occurs between the ages of six and twelve), when the rational capacity to find solutions to life's problems appears. This sense is related to abstract thinking and planning, and allows people to cope effectively with the demands of reality.

7. Propriate Striving or Motivation (the core problem for the adolescent according to Allport; normally develops after twelve). It is the selection of occupation or other life goal, when adolescents know that their future must follow a plan, and in this sense it makes them lose their childhood. It is related to forming an ideal view of our self, and direction for future development (where an intentional drive takes over from natural desires and impulses) and is more closely related to reflecting interest, tendency, disposition, anticipation, planning, problem solving, focus and intention. This is our self as goals, ideals, plans, vocations, callings, a sense of direction, and a sense of purpose. 
8. Self as Knower or as Subject of Knowledge - a feature that, according to Allport, rises above the other propriate functions and synthesises them. It lies in the fact that man knows not only the objects of matter, but also himself, resulting in the development of man's capacity for self-knowledge and self-awareness. The knower (thinking agent) "rides" on top of them. The thinker is different from his or her thoughts.

The first three functions - senses of body, of self-identity and and self-esteem - are developed in early childhood. The other functions are enlarged over time, and depend on individual features of men, own life paths, or experience. Gordon Allport emphasized that at any stage of personality development, not just one propriative function is developed but a fusion of several. For example, in the situation of maturation of self-understanding, the rational subject of proprium, personal motivation (striving), an extension of "ego", and self-image are activated. According to Allport, proprium is a positive quality of human nature, related to creative personality development. He was simultaneously a believer in the uniqueness of the individual and the wholeness of personality.

\section{Multi-layered model of personality}

Corr and Mattews (cited in Corr, 2010) noted in their Introduction to the Cambridge Handbook of Personality Psychology:

A persistent theme... has been the multi-layered nature of personality, expressed in individual differences in neural functioning, in cognition and information-processing, and in social relationships. Abnormal personality too is expressed at multiple levels. Despite the inevitable difficulties, a major task for future research is to develop models of personality that integrate these different processes.

The multilayered presentation of the human being is represented by the collective unconscious depicted in traditional souvenirs, such as the "Matryoshka" doll that was popular not only in Russia, but also in Japan and other Eastern European countries (Fig. 1).
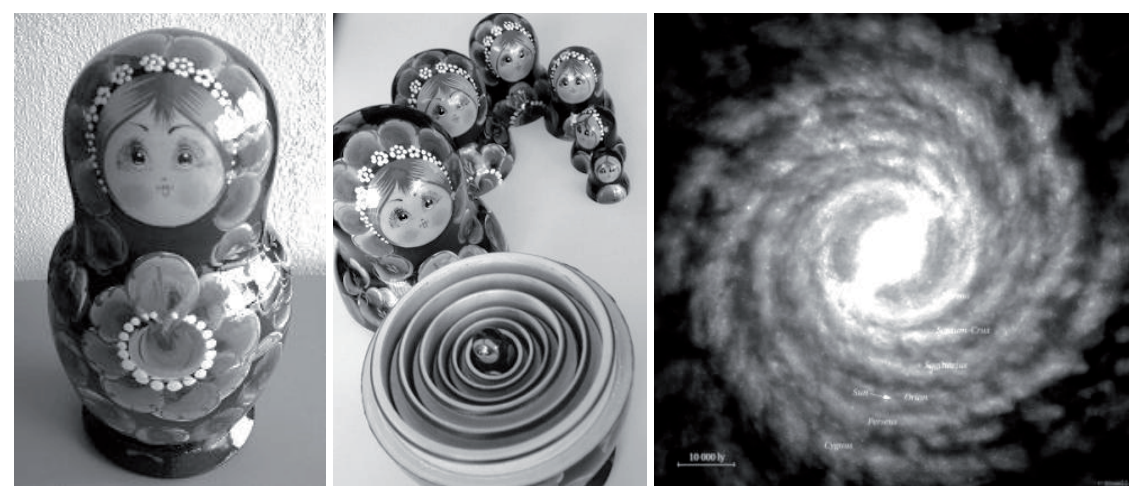

Figure 1. "Matryoshka", a traditional Eastern souvenir, represents a multilevel personality model (bio-psi-social-historical). Its interior is reminiscent of a Universe model (photo and picture adapted by author). 
Despite some common personality traits in persons and their similarity in body composition, the most integrative picture is obtained at the level of individual description, performed by singular case studies, such as was described by the neuropsychologist Luria $(1968,1972)$ and by Sacks $(1985)$. Each person is a microcosm, a mini-Universe that reflects the external world with individual features. The exteroceptive senses "adjust" our perception and reduce the individual internal variability which is more fully expressed by the proprioceptive sense, and is independent of external influence (Enoka, 2002).

Directional deviations in transversal plane based on visual (PV) and proprioceptive $(P)$ only feedback

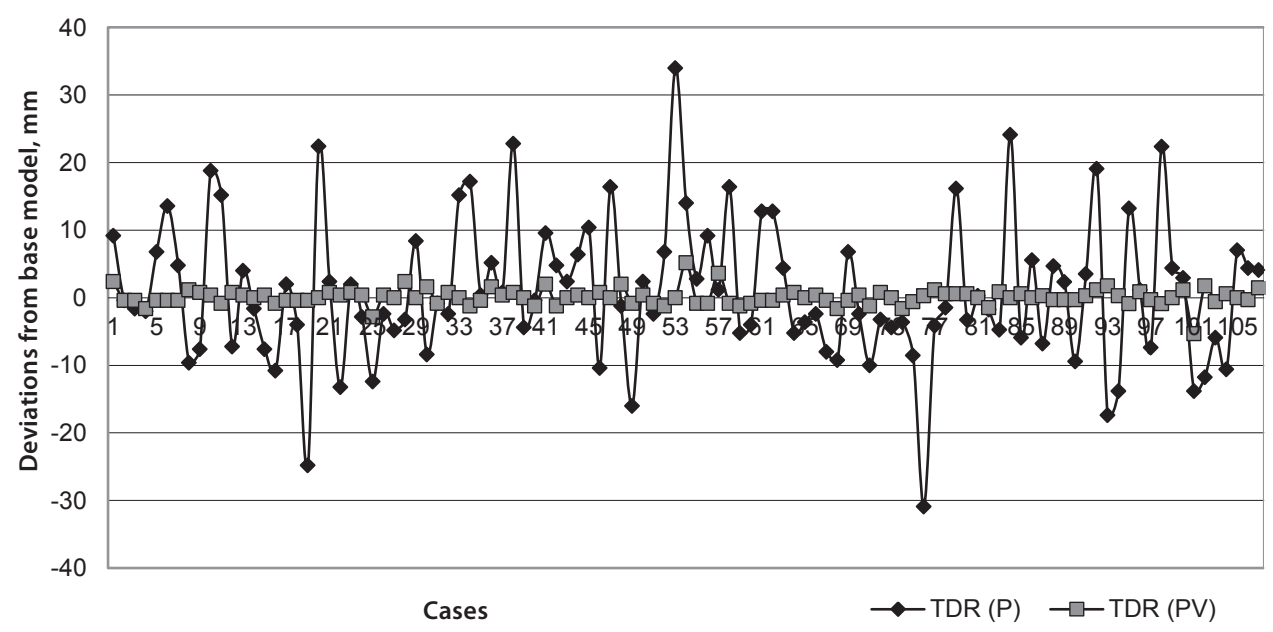

Figure 2. Comparative graphic of the subject's performances (X-axis) in different sensory conditions: $\mathrm{PV}$ - proprioceptive-visual and $\mathrm{P}$ - proprioceptive only.

As an example of the range of individual variability between fine graphomotor performance of individuals in condition with vision (PV) and in proprioceptive $(\mathrm{P})$ only, when the participant did not see either the graphical feedback of his drawings nor his own hand position is represented in Figure 2 (Tous-Ral \& Liutsko, 2012; Liutsko \& Tous-Ral, 2012). MANOVA analysis has shown the significant differences between fine graphomotor performances when comparing both sensory conditions (PV vs. P) (Tous-Ral, Muiños, Liutsko, \& Forero, 2012). For this reason, also continuing the Mira y Lopez tradition, the proprioceptive sense was used by Prof Tous (2008) to create the Proprioceptive Diagnosis of Temperament and Character (Tous Ral, Muiños, Tous López, \& Tous Rovirosa, 2012) which can complement verbal techniques in personality assessment thus providing, in a sum, a global picture of a person.

\section{Learning with the help of proprioception and automatic behaviour}

Proprioception plays an important role in our daily lives (Goble, Noble, \& Brown, 2010). Its automatic performance is done mainly on the unconscious level: visceral organ regulation (respiration, heart function, etc.), locomotive synchronization for 
balance, and optimal kinematics in humans (we have an autopropulsive mechanism that consists of about 600 muscles, 200 bones and several hundred tendons) or in animals (how a centipede coordinates all its legs) (Fig. 3).

Proprioception is a basis for acquiring automatic knowledge, sometimes called know-how or "embodied" knowledge (Barsalou, 2008; Sebanz, Knoblich \& Humphreys, 2008 of the kind based on practical experience, daily routine activity, or professional skills. When we start to learn a new skill, such as cycling or driving, we need to see our feet pedalling or our hand changing the gear; however, with time and repeated practice we do it on the proprioceptive level and without visual guidance, apparently working on autopilot (Lee, Swinnen, \& Serrien, 1994). Without proprioception we would have no professional pianists, painters, ballet dancers, circus acrobats, or sportsmen.
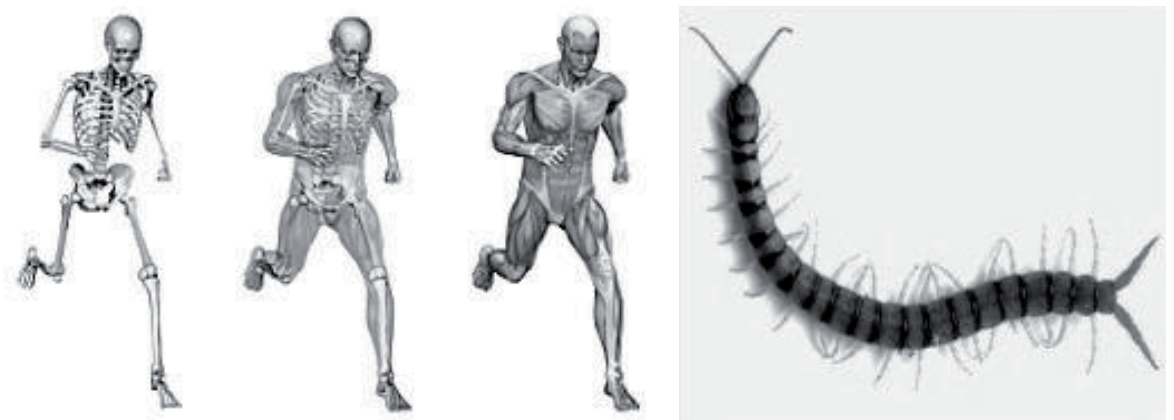

Figure 3. Muscular-joint-skeletal human presentation and centipede (picture adapted by author).

Practical knowledge, due to proprioceptive sense, becomes "embodied" knowledge, allowing us to be less stressed during multiple and/or prolonged activities. Such habits and skills start to work automatically and without our brain control, as reflexions. In order to appreciate this, we could mention the examples of automatized movements from the experiments of the renowned Russian physiologist Sechenov, carried out more than 100 years ago (Sechenov, 2013):

1) When a decapitated frog's leg was pinched, the frog tried to remove the leg from the stimulus; however, when the leg was daubed with an acid, the frog scrubbed the leg with another part of the body.

2) When a frog without a brain was pinched on the table, it started to crawl in order to escape from the stimuli; however, when it was pinched in water, the frog started to swim.

These examples were of "rational" behaviour that worked as an automatic reflex.

Corr (2010) pointed out, in consideration of importance, multiple levels of behavioural control that require recognition of both (a) the relationship between automatic (reflexive or pre/non-conscious) and controlled (reflective, often with conscious representation) processes and (b) their time pattern (or lateness of controlled processes and their awareness). Modern researchers have shown that we become aware of our actions, or that controlled processing comes, with a lag 
time of 300-500 msec after the action had been started, i.e. mind followed by brain events (Corr, 2010). In Libet's experiments (cited in Corr, 2010), the removal of the hand from a hot stove occurred before awareness of the hand touching the stove. According to Gray's theory (2004), the control of action consisted of late error detection and correction; i.e. it was related to cognitive processes that interrupt undesirable automatic brain-behaviour routines and correct for more adaptive ones.

Mechanisms of behavioural control (e.g. automatic vs. controlled processing) are fundamental in psychological explanation; and individual differences in these mechanisms may be assumed to play an equally important role in personality psychology. (Corr, 2010).

Corr (2010) stresses the importance of distinguishing between information obtained by different types of psychometric. While lexical tests (Big Five or others) can preferentially reflect controlled processing and conscious awareness that codifies important features of society (e.g. appreciation of artistic beauty; Openness), the importance of social interactions (Agreeableness), and following the norms and ethics established by society (Conscientiousness), then temperamental and biological measures (BIS/BAS and DP-TC), on the other hand, would reflect more dispositional, emotionally-based responses. This information can be more closely related to emotional control (Neuroticism) and Extroversion (it belongs to more automatically-elicited preference, since the preference to go to a lively party or to stay at home is not based on rational judgment, but more emotionally: likes and dislikes). We act as we feel and wish at a given moment, but when we reply to questionnaires we can fake an answer that can be more "rational" for our observers (especially in cases of special goals and interests, like applying for an attractive job). In this case the replies correspond more to our socially "desirable" behaviour than to our real selves. In this case we "supplement" or "modify" our behaviour to fit that accepted by the "norms" and "values" of the specific socio-historical culture of time.

To see how these values and qualities really are formed in children's behaviour, I would like to return to Sechenov's renowned work "Reflexi golovnogo mozga" (Sechenov, 2013). He explained that during development, children first like the "images" of their toys, and wish to be like their "heroes". Later, they transfer the qualities of these heroes to their own qualities as a model to follow: to be strong and without fear, to be generous and sympathetic, kind and honest, etc. The child, fusing with the image of his favourite hero, identifies with its qualities and transfers them to his own identity. Playing with his hero (it can be a reproduction of the live examples that surround him as well: parents, close friends or significant teacher figures, imaginary heroes from books, movies or videogames), the child repeats many times the actions of his "model", and words and attitudes toward to others, i.e. visual, auditory and action behaviour. Prof Ivannikov (2010) also mentioned in his lecture dedicated to achieving a socio-historical experience the importance of sense in the main activity of children: "Game (playing) is that type of activity of a child, in which the norms of human relationships are discovered and supported." 


\section{Embodied cognition}

The issue of embodiment and situated cognition has arisen again recently as a core idea that perception, action, and cognition are shaped by the social context in which we engage with others, suggesting that cognition should be investigated at the group level rather than at the individual level (Knoblich, 2008; Sebanz, Knoblich, \& Humphreys, 2008). Returning to the developmental growth of children, Sechenov (2013, originally published 1863) described how the "passion" of toys and play passes with time, although deep convictions relating to this behaviour remain and can acquire other forms. The boy who played a lot with knights, fighting for high moral values, will conserve his deep conviction to fight for justice: as a soldier, general or advocate, for example, or simply as a noble person. The Russian pedagogue Sukhomlinskij, in his work "I give my heart to children" (1985), said of education:

Children should live in the world of beauty, fairy tales, music, painting, fantasy, creativity (translated by author, Liutsko, 2013).

And the following passage from Leo Tolstoy has become an aphorism in the field of education (Aphorism, 2007):

All moral education of children comes down to good example. If you live well or intend to live well, and in so far as you succeed in your "goodness" in life, children will have a good education (translated by author).

A modern proof of one aspect of such a "visual" fusion is the activation of somatosensory parts of the brain, relating to an action a person simply watches in a video game, on the TV, or in a video recording (Lee, Swinnen, \& Serrien, 1994; Repp \& Knoblich, 2004; Scholz, 2010); this activation is more pronounced when the person is practising this type of activity, as compared to reading novels (Repp \& Knoblich, 2004). Moreover, the so-called "mirror system" (formed by mirror neurons) matches observation and execution in goal-related actions, and appears to be to some degree a "functional" equivalent, somewhere between simulating, observing and performing an action (Sebanz, Knoblich, Stumpf, \& Prinz, 2005). People tend to reproduce automatically by internal or imagined replication of the posture they observe, mimicking facial expressions and gestures; this covert imitation requires the use of implicit knowledge of one's own body (Bosbach, Knoblich, Reed, Cole, \& Prinz, 2006). In addition, the use of expert models also has considerable pedagogical support by means of a perceptual blueprint, a precise representation of the perceptual demands of the task. The suggestion that viewing repetitious performances of skills would "imprint into" the behaviour of observers was checked by Lee, Swinnen, \& Serrien (1994). They found that the performance of persons who observed the skill prior to their own reproduction of it were better than novices who had not seen it before (Lee, Swinnen, \& Serrien, 1994).

To sum up, as has been shown here, proprioceptive sense plays a crucial role in education and formation, and is a basis of individual differences and personality construct. Due to the scarcity of investigations relating to proprioception in psychology, this article can help to connect different, interrelated areas (generally body-mind paradigm) and show the importance of studying this little-known sense more in the future. 


\section{Acknowledgment}

I am thankful to the University of Barcelona for the scholarship provided for my research, and to Dr Tous for directing it.

\section{References}

Allport, G. (2006). In Wikipedia. Retrieved September, 28, 2012, from http://ru.wikipedia.org/ wiki/\%D0\%9E\%D0\%BB\%D0\%BF\%D0\%BE\%D1\%80\%D1\%82,_\%D0\%93\%D0\%BE\%D1\% 80\%D0\%B4\%D0\%BE\%D0\%BD [In Russian].

Aphorism. (2007). Retrieved on-line October 20, 2012, from: http://www.aphorisme.ru/ comments $/ 4226 / ? \mathrm{q}=967 \& \mathrm{a}=4226$

Arena, J., Sherman, R., Bruno, G., \& Smith J. (1990). The relationship between situation stress and phantom limb pain: Cross-lagged correlation data from six month pain logs. Journal of Psychosomatic Research, 34(1), 71-77. doi: 10.1016/0022-3999(90)90009-S

Barsalou, L. W. (2008). Grounded cognition. Annu. Rev. Psychol., 59, 617-645. doi: 10.1146/annurev.psych.59.103006.093639

Bohm, D. (2007). Self, society and proprioception. Retrieved October 5, 2012, from http://thinkg. net/david_bohm/self_society_proprioception.html

Bosbach, S., Knoblich, G., Reed, C. L., Cole, J. \& Prinz, W. (2006). Body inversion effect without body sense: Insights from deafferentation. Neuropsychologia, 44, 2950-2958. doi: 10.1016/j. neuropsychologia.2006.06.018

Botvinick, M. (2004). Probing the neural basis of body ownership. Science, 305(5685), 782-783. doi: $10.1126 /$ science.1101836

Corr, P. J. (2010). Automatic and Controlled Process in Behavioural Control: Implications for Personality Psychology. Eur. J. Pers, 24, 376-403. doi: 10.1002/per.779

Enoka, R. M. (2002). Neuromechanics of human movement. USA: Human Kinetics.

Goble, D. J., Noble, B. C., \& Brown, S. H. (2010). Where was my arm again? Memory-based matching of proprioceptive targets is enhanced by increased target presentation time. Neuroscience Letter, 481(1), 54-58. Epub 2010 Jun 25. Retrieved from http://www.ncbi.nlm.nih. gov/pubmed/20600603

Gray, J. A. (2004). Consciousness: Creeping up on the hard problem. Oxford: Oxford University Press.

Ivannikov, V. A. (2010). Osnovi psijologii. Kurs lekcij.. [Bases of psychology. Series of lectures.] St.Petersburg: Piter.

Juhel, J. \& Neiger, H. (1993). The illusory movement sensation paradigm: Some personality correlates. Personality and Individual Differences, 14, 293-296. doi: 10.1016/0191-8869(93) $90210-\mathrm{T}$

Kilteni, K., Normand, J.-M., Sanchez-Vives, M. V., \& Slater, M. (2012). Extending body space in immersive virtual reality: A very long arm illusion. PLoS ONE 7(7): e40867. doi:10.1371/ journal.pone.0040867

Knoblich, G. (2008). Motor contributions to action perception. In R. Klatzky, B. MacWhinney, \& M. Behrmann (Eds.): Ebodiment, ego-Space, and action, The $34^{\text {th }}$ Carnegie symposium on Cognition. New York: Psychology Press.

Lackner, J. R. (1988). Some proprioceptive influences on the perceptual representation of body shape and orientation. Brain: 111, 281-297. doi: 10.1093/brain/111.2.281

Lee, T. D., Swinnen, S.P., \& Serrien, D.J. (1994). Cognitive effort and motor learning. Quest, 46(3), 328-344. doi: 10.1080/00336297.1994.10484130 
Leonov, A. A. \& Lebedev, V. I. (1965). Ob orientacii cheloveka v kosmicheskom prostranstve [About human orientation in cosmic space]. Kosmicheskie Issledovaniya [Cosmic Research], $3(6)$.

Leonov, A., Lebedev, V., Belitsky, B. (2001). Space and time perception by the cosmonaut. University Press of the Pacific.

Liutsko, L. (2013, in press). Age and sex differences in proprioception based on fine motor precision. $\mathrm{PhD}$ dissertation (directed by Tous, J.M.). Barcelona: University of Barcelona.

Longo, M. R., Kammers, M. P. M., Gomi, H., Tsakiris, M., \& Haggand, P. (2009). Contraction of body representation induced by proprioceptive conflict, Current Biology, 19(17), 727-728. doi: 10.1016/j.cub.2009.07.024

Luria, A. R. (1968). The mind of mnemonist. New York: Basic Books.

Luria, A. R. (1972). The man with a shattered world. New York: Basic Books.

Matthiews, P. B. C. (1982). Where does Sherrington's "muscular sense" originate? Muscles, corollary discharges? Annual Review of Neuroscience, 5, 189-218. doi: 10.1146/annurev. ne.05.030182.001201

Phantom limb. (2009) In Wikipedia. Retrieved September 25, 2012, from http://en.wikipedia. org/wiki/Phantom_limb

Proprioception. (2007). In New World Encyclopedia. Retrieved Augost 25, 2012, from http:// www.newworldencyclopedia.org/entry/Proprioception

Ramachandran, V.S., \& Hirstein, W. (1998). The perception of phantom limbs. Brain 121: 16031630. doi:10.1093/brain/121.9.1603 PMID 9762952

Repp, B. H. \& Knoblich, G. (2004). Perceiving action identity: How pianists recognize their own performances. Psychol. Sci., 15, 604-609. doi: 10.1111/j.0956-7976.2004.00727.x

Sacks, O. W. (1985). The Man who Mistook his Wife for a Hat and Other Clinical Tales. New York: Summit Books.

Sebanz, N., Knoblich, G., \& Humphreys, G. W. (2008). “Cognitive Ethology” for humans: Inconvenient truth or attentional deficit? British Journal of Psychology, 99, 347-350.

Sebanz, N., Knoblich, G., Stumpf, L. \& Prinz, W. (2005). Far from action-blind: Representation of others' actions in individuals with autism. Cognitive Neuropsychology, 22(3/4), 433-454. doi: $10.1080 / 02643290442000121$

Sechenov, I. M. (2013, originally published in 1863). Refleksy golovnogo mozga: Popytka svesti sposob proishozhdenia psijogdenia psijicheskih yavenij na fisiologicheskie osnovy. S biografiej I. M. Sechenova [The brain's reflexes: The attempt to bring the means of origin of psychic phenomena to the physiological basis. With biography of Sechenov. I.M.], 6th edition. Moscow: LIBROKOM.

Sherrington, Ch. (1906). The integrative action of the nervous System. New Haven: Yale University Press. Reprinted 1947. Cambridge: Cambridge University Press.

Schmidt, R. F. (1984). Somatoviceralnaia chuvstvitelnost [Somatovisceral sensitivity] Fundamentals of Sensory Physiology, 108-115.

Scholz, W. (2010). The phenomenology of movement: Action, proprioception, and embodied knowledge. $\mathrm{PhD}$ thesis (directed by Prof Evan Fales), University of Iowa. Retrieved from http://ir.uiowa/etd/736

Sukhomlinskij, V. A. (1985). Serdce otdayu detiam [The heart give to children]. Radzianska shkol.

The man who lost his body. (1998). BBC documentary film, Retrieved on-line from: http://www. youtube.com/watch?v=FKxyJfE831Q

Tous-Ral, J. M., \& Liutsko, L. (2012). Quantified differences in hand drawing precision from exteroceptive (visual) and proprioceptive versus proprioceptive feedback only. In Books of abstracts of Moscow International Congress dedicated to the 110th anniversary of A.R. Lu- 
ria's birth, (p. 101). Conferences "A.R. Luria and the development of the world psychological science", "A.R. Luria and modern neuropsychology" $\left(29^{\text {th }}\right.$ of November $-1^{\text {st }}$ December, 2012). Lomonosov Moscow State University, Psychology Department.

Liutsko, L. \& Tous-Ral, J. M. (2012). Personality traits based on fine motor individual behaviour. In Eds. Kupreichenko, A.B. and Shtroo, V.A Psihologiia Individual 'nosti. Materialy' SHM Mserossii 'skoi' nauchnoi' konferentcii [Psychology of Individuality. The Materials of 4th Russian scientific conference], (22-24 November), p. 322 (abstract in English). Moscow: Logos.

Tous-Ral, J. M., Muiños, R., Liutsko, L., \& Forero, C. G. (2012). Effects of sensory information, movement direction and hand use on fine motor precision. Perceptual and Motor Skills, 115(1), 261-272. doi: 10.2466/25.22.24 PMS.115.4.261-272

Tous, J. M. (2008). Diagnostico Propioceptivo del Temperamento y el Carácter DP-TC [Proprioceptive diagnosis of temperament and character]. Barcelona: Lab. Mira y López. Department of Personality, Assessment and Psychological Treatments, University of Barcelona.

Tous Ral, J. M., Muiños, R., Tous López, O., \& Tous Rovirosa, J. M. (2012). Diagnóstico propioceptivo del temperamento y el carácter [Proprioceptive diagnostic of temperament and character]. Barcelona: Universidad de Barcelona.

Received: 07 November 2013

Accepted: 19 November 2013

Available Online: 27 November 2013 